\title{
CORRECTION
}

\section{Correction to: Compartment pressures in children with normal and fractured lower extremities}

\author{
Hannah Rachel Bussell ${ }^{1}$ (D) Christoph Alexander Aufdenblatten ${ }^{2} \cdot$ Ulrike Subotic $^{1} \cdot$ Markus Kalisch $^{3} \cdot$ Georg Staubli $^{4}$. \\ Daniel Max Weber ${ }^{5}$. Sasha Job Tharakan ${ }^{1}$
}

Published online: 18 February 2019

(c) Springer-Verlag GmbH Germany, part of Springer Nature 2019

\section{Correction to: \\ European Journal of Trauma and Emergency Surgery https://doi.org/10.1007/s00068-019-01082-9}

The original version of this article unfortunately contained a mistake in the author name Sasha Job Tharakan. The corrected name is given above.

The original article can be found online at https://doi.org/10.1007/ s00068-019-01082-9.

\section{Hannah Rachel Bussell}

hannah.bussell@kispi.uzh.ch

1 Department of Pediatric Surgery, General and Thoracic Surgery, University Children's Hospital Zurich, Steinwiessstrasse 75, 8032 Zurich, Switzerland

2 Trauma and Orthopaedic Surgery, University Children's Hospital Zurich, Zurich, Switzerland

3 Seminar for Statistics, ETH Zurich, Zurich, Switzerland

4 Department of Emergency Medicine, University Children's Hospital Zurich, Zurich, Switzerland

5 Pediatric Hand Surgery, University Children's Hospital Zurich, Zurich, Switzerland 